\section{AB1087 THE RELATIONSHIP BETWEEN FEMORAL CARTILAGE THICKNESS AND AMYLOIDOSIS IN PATIENTS WITH FAMILIAL MEDITERRANEAN FEVER: PRELIMINARY STUDY}

Halise Hande Gezer', Didem Erdem ${ }^{1}$, Sevtap Acer Kasman ${ }^{1}$, Hatice Sule Baklacioglu², Mehmet Tuncay Duruöz ${ }^{1} .{ }^{1}$ Marmara University School of Medicine, Department of Physical Medicine and Rehabilitation, Rheumatology Division, Istanbul, Turkey, ${ }^{2}$ Samsun Training and Research Hospital, Rheumatology, Samsun, Turkey

Background: Familial Mediterranean fever (FMF) is the most common hereditary inflammatory disease characterized by recurrent attacks of fever and serositis. The most devastating complication of FMF is amyloidosis, leading to chronic renal failure (CRF). The amyloid protein may accumulate in many tissues including the cartilage, particularly in the kidneys. Sonographic femoral cartilage thicknesses (FCT) was evaluated in many chronic rheumatic diseases and was shown to be thinner than healthy individuals.

Objectives: The aim of this study was to determine FCT in FMF patients and healthy individuals and to assess the relationship of FCT with the development of amyloidosis and clinical features.

Methods: Patients diagnosed with FMF according to the Tel-Hashomer criteria were included in the study. Patients with trauma and other inflammatory disease and patients with a history of knee operation were excluded. Femoral cartilage thickness of both knees was measured with a 7-12 $\mathrm{MHz}$ linear probe in maximum knee flexion. Three mid-point measurement were obtained from each knees: lateral femoral condyle (LFC), intercondylar area (ICA) and medial femoral condyle (MFC). Clinic characteristics of the patients including disease duration, medications, comorbid conditions, amyloidosis, CRF, FMF gene mutation, arthritis, sacroiliitis, PRAS score and physical activity scores were recorded. Descriptive analysis was performed for all parameters. The Mann-Whitney U-test and Spearman's correlation coefficient were used in statistical analysis. $\mathrm{P}<0.05$ was considered statistically significant.

Results: A total of 45 patients with FMF (35 women, 10 men) and 20 age-sex-BMI matched controls (14 women, 6 men) were enrolled in this study. The mean age of the patients and controls were 38.2 (SD:12.2) and 37.5 (SD:8.5) years, respectivelly. Amyloidosis occurred in 7 patients $(15.6 \%)$, CRF in $3(6.7 \%)$, sacroilitis in $10(22.2 \%)$ and arthritis in 16 $(35.6 \%)$. Disease activity was mild in $48.9 \%$, moderate in $20 \%$ and severe $22.2 \%$ of the patients. The mean FCT in centimeters values in the FMF and control groups were as follows: on the right side LFC 0.19 (SD:0.03) and 0.22 (SD:0.05), ICA 0.23 (SD:0.05) and 0.24 (SD:0.06), MFC 0.20 (SD:0.04) and 0.24 (SD:0.06); on the left side LFC 0.19 (SD:0.03) and 0.21 (SD:0.03), ICA 0.22 (SD:0.05) and 0.24 (SD:0.06), MFC 0.19 (SD:0.03) and 0.22 (SD:0.04). Patients with FMF had decreased cartilage thickness at the lateral condyle of both knees $(p<0.05)$ and medial condyle of the left knee $(p<0.05)$ compared with controls. FCT measurements were similar in patients with or without arthritis, sacroilitis, amyloidosis and CRF. Physical activity scores were significantly correlated with the left LFC $(r=0.309)$. Total protein in 24hour urine showed a highly negative correlation with left LFC ( $r=-0.718)$. Conclusion: These findings suggest that patients with FMF have decreased FCT compared with controls. There is no significant relationship between the FCT and amyloidosis, it has significant relation with proteinuria level.

\section{REFERENCES}

[1] Ozcakar, L., et al., Femoral cartilage thickness measurements in healthy individuals: learning, practicing and publishing with TURK-MUSCULUS. J Back Musculoskelet Rehabil, 2014. 27: p. 117-24.

[2] Mitrovic, D.R., et al., Amyloid deposits in human knee and hip joints. J Rheumatology International. 1985. 5(2): p. 83-89.

Disclosure of Interests: Halise Hande Gezer: None declared, Didem Erdem: None declared, Sevtap Acer Kasman: None declared, Hatice Sule Baklacioglu: None declared, Mehmet Tuncay Duruöz Grant/research support from: Abvie, Speakers bureau: Novartis, AMGEN, Abdi İbrahim, Illko DOI: 10.1136/annrheumdis-2019-eular.6370

\section{$\mathrm{AB} 1088$ \\ HEMOGRAM PARAMETER CHANGES DURING THE ATTACK AND THE REMISSION IN FAMILIAL MEDITERRANEAN FEVER PATIENTS}

Emel Gönüllü ${ }^{1}$, Yunus Emre Özer², Ünal Erkorkmaz ${ }^{3} .{ }^{1}$ Sakarya University, Internal Medicine Rheumatology Department, Sakarya, Turkey; ${ }^{2}$ Sakarya University, Internal Medicine Department, Sakarya, Turkey; ${ }^{3}$ Sakarya University, Biostatistics, Sakarya, Turkey

Background: Familial Mediterranean Fever (FMF) is the most common monogenic autoinflammatory disease. Disease-specific symptoms are fever and polyserositis attacks (1). The most important complication in the long term is amyloidosis (2). Many cytokines and acute phase reactants have been studied in patients with familial Mediterranean fever. Erythrocyte sedimentation rate $(E S R)$, c-reactive protein $(C R P)$, serum amyloid A (SAA) and fibrinogen levels increase during attack and return to normal values after the attack $(3,4)$. Biomarkers that are useful on the course of the disease and the development of amyloidosis are still needed.

Objectives: In this study, we aimed to observe the changes reflected in the hemogram parameter values during the remission and attack periods of FMF patients.

Methods: Study included 67 patients who met the FMF Tel-Hashomer criteria. The patients with available results of both remission and attack periods were included in the study.Since the distribution of all continuous variables used in the study as a statistical method was not suitable for normal distribution, Wilcoxon $T$ test was used to investigate the difference in hematological variables during remission and attack periods

Results: 21 of the patients were male and 46 were female. The mean age of the male patients was $41.57 \pm 11.08$ and the female patients were $35.84 \pm 11.75$. The mean age of all patients was $38.18 \pm 11.20$ years. There was a statistically significant difference between neutrophils in the comparisons of hematological variables between remission and episode periods of familial Mediterranean Fever patients $(p<0.001)$. No significant difference was found in terms of other variables (Table 1).

Conclusion: Our study does not support that neutrophil/lymphocyte ratio, MPV and PDW values may be helpful in the attack. Significant differences in neutrophil counts suggest that further studies are needed to show neutrophil cell morphology, number, and function in FMF patients.

\section{REFERENCES}

[1] Özen S, Batu ED, Demir S. Familial Mediterranean Fever: Recent Developments in Pathogenesis and New Recommendations for Management. Front Immunol. 2017 23;8:253.

[2] Sönmez HE, Batu ED, Özen S. Familial Mediterranean fever: current perspectives.J Inflamm Res. 2016 17;9:13-20.

[3] Özer S, Yılmaz R, Sönmezgöz E, Karaaslan E, Taşkın S, Bütün İ, Demir O. Simple markers for subclinical inflammation in patients with Familial Mediterranean Fever.Med Sci Monit. 2015 23;21:298-303.

[4] Tunca M, Kirkali G, Soyturk M, et al. Acute phase response and evolution of familial Mediterranean fever. Lancet. 1999;353:1415.

Abstract AB1088 Table 1. Distribution of hematological parameter characteristics of patients with remission and attack episodes

\begin{tabular}{lcccc}
\hline & $\mathbf{n}$ & Remission & Attack & $\mathbf{p}$ \\
\hline CRP(mg/L) & 54 & $3.23[3.03-4.20]$ & $27.90[17.60-51.10]$ & $<0.001$ \\
RDW(\%) & 54 & $16.10[15.20-17.30]$ & $16.00[14.80-17.00]$ & 0.157 \\
MPV(fL) & 54 & $7.52[7.02-8.20]$ & $7.50[6.85-8.29]$ & 0.054 \\
PDW(\%) & 54 & $17.70[17.30-18.30]$ & $17.70[17.20-18.20]$ & 0.185 \\
Neutrophil( $\mu \mathrm{L})$ & 54 & $3815.00[2980.00-$ & $4740.00[3330.00-$ & $\mathbf{0 . 0 4 7}$ \\
& & $4660.00]$ & $6180.00]$ & \\
Lymphocyte $(\mu \mathrm{L})$ & 54 & $2035.00[1700.00-$ & $1900.00[1500.00-$ & 0.060 \\
& & $2400.00]$ & $2210.00]$ & \\
Neutrophil/Lymphocyte & 54 & $0.79[0.57-1.47]$ & $1.14[0.90-1.25]$ & 0.137 \\
Ratio & & & & \\
\hline
\end{tabular}

Disclosure of Interests: None declared

DOI: 10.1136/annrheumdis-2019-eular.2096 